\title{
O DANO MORAL COLETIVO NAS RELAÇÕES DE CONSUMO E A VISÃO DOS TRIBUNAIS
}

\section{COLLECTIVE DAMAGE IN MORAL CONSUMER RELATIONS AND THE VISION OF COURTS}

\author{
${ }^{1}$ Carolina Medeiros Bahia
}

${ }^{2}$ Heloísa Gomes Medeiros

\section{RESUMO}

Constatando a falta de consenso doutrinário em torno do tema e a prática de se realizar, nesta esfera, uma mera transposição da dogmática tradicional, sem as necessárias adequações, o presente artigo propõe-se a discutir o dano moral coletivo nas relações de consumo, enfocando: o conceito atual de dano moral; o caráter aberto da categoria dos direitos da personalidade, que também passa a abarcar os direitos difusos e coletivos; a caracterização e as especificidades do dano moral coletivo no Direito do Consumidor e, por fim, a sua compreensão na jurisprudência recente do Superior Tribunal de Justiça.

Palavras-Chave: Dano Moral; Direito do Consumidor; Direitos da Personalidade;

Direitos Difusos e Coletivos.

\begin{abstract}
Before the lack of doctrinal consensus about the subject and the practice of performing, in this sphere, a mere transposition of traditional dogmatic, without the necessary adjustments, this article proposes to discuss the collective moral damage in consumer relations, focusing on : the current concept of moral damage; the open character of the category of personal rights, which also cover the diffuse and collective rights; the characterization and the specifics of collective moral damage to consumer law and, finally, their understanding in the recent case law of the Supreme Court.
\end{abstract}

Keywords: Moral damage; Consumer Law; Personality Rights; Diffuse and Collective Rights.

\footnotetext{
${ }^{1}$ Doutora em Direito pela Universidade Federal de Santa Catarina - UFSC, Santa Catarina (Brasil). Professora no Curso de Graduação e nos Programas de Mestrado Acadêmico e Profissional pela Universidade Federal de Santa Catarina - CCJ/UFSC, Santa Catarina (Brasil).

E-mail: carolmbahia@gmail.com

2 Doutoranda em Direito pela Universidade Federal de Santa Catarina - UFSC, Santa Catarina (Brasil). Pesquisadora pela Universidade Federal do Paraná - GEDAI/UFPR, Paraná (Brasil).

E-mail: medeiroshg@gmail.com
} 


\section{INTRODUÇÃO}

Verifica-se, na atualidade, uma verdadeira expansão das áreas de interesses protegidos pela ordem jurídica como consequência da emergência de novas esferas de projeção da dignidade humana. Esse fenômeno é particularmente perceptível na seara dos direitos coletivos.

O avanço na proteção dos direitos coletivos, difusos e individuais homogêneos e a necessidade de reparar as lesões que os afetam, gerou, paulatinamente, o reconhecimento legal, doutrinário e jurisprudencial do denominado dano moral coletivo.

Nesta linha, destaca-se o pioneirismo do Código Brasileiro de Defesa do Consumidor, que, no início da década de 90, delineou um sistema avançado de responsabilidade civil do fornecedor, buscando, a um só tempo, reparar os danos materiais e morais que afetem o consumidor tanto na sua esfera individual quanto coletiva.

Contudo, passados mais de vinte e cinco anos desta afirmação e apesar dos expressivos avanços na doutrina e na jurisprudência, constata-se ainda diversas dificuldades na caracterização do dano moral coletivo incidente nas relações de consumo, o que termina, muitas vezes, por prejudicar a tecnicidade e a previsibilidade das decisões que que apreciam essas demandas.

Muitos desses problemas decorrem, por um lado, da própria falta de consenso doutrinário em torno do que se compreende hoje como dano moral e, por outro, da prática ainda muito comum de se realizar, nesta esfera, uma mera transposição da doutrina tradicional do dano moral, sem as necessárias adequações que o caráter transindividual dos interesses difusos e coletivos passa a demandar.

Deste modo, são objetivos desse artigo: discutir a conceituação atual do dano moral; destacar o caráter aberto da categoria dos direitos da personalidade, que também abarca os direitos difusos e coletivos; caracterizar o dano moral coletivo no Direito do Consumidor e, por fim, investigar a compreensão do dano moral coletivo na jurisprudência recente do Superior Tribunal de Justiça. 


\section{DANO MORAL: UMA DIFÍCIL CONCEITUAÇÃO.}

A reparação do dano moral ganhou um grande incremento com a Constituição Federal de 1988, que previu nos incisos V e X do art. 5º a possibilidade de indenização pelo dano exclusivamente moral .

A reparabilidade deste dano também está expressa no art. 186 do Código Civil brasileiro que dispõe que: "aquele que, por ação ou omissão voluntária, negligência ou imprudência, violar direito e causar dano a outrem, ainda que exclusivamente moral, comete ato ilícito".

Do mesmo modo, não há qualquer dúvida a respeito da possibilidade de sua reparação e da cumulação entre o dano patrimonial e o moral oriundos do mesmo fato. Este entendimento encontra-se sumulado, desde 1992, pelo Superior Tribunal de Justiça. ${ }^{3}$

No entanto, superados os debates em torno da sua reparação e cumulação, persistem ainda hoje muitas discussões em torno da melhor forma de se conceituar o dano moral.

Muito embora a dogmática civil clássica tenha atrelado o dano moral a uma concepção subjetiva, baseada na ideia de sofrimento individual, verifica-se que, na atualidade, a doutrina e a jurisprudência têm alterado esta concepção e estendido a sua aplicação para a pessoa jurídica e para grupos de pessoas. Prova disso são a redação do art. 52 do Código Civil pátrio que determina que: "Aplica-se às pessoas jurídicas, no que couber, a proteção dos direitos da personalidade" e a súmula 227 do Superior Tribunal de Justiça, que preleciona que a pessoa jurídica também pode ser vítima de dano moral.

Apesar de a maior parte das definiçõoes de dano moral ainda recorrer à noção de sofrimento humano não gerado por uma perda pecuniária, essa compreensão tem sido alvo de severas críticas por se revelar excessivamente ampla e permitir que quase todo incômodo ou desconforto possa configurar dano moral.

Nesta linha, Maria Celina Bodin de Moraes (2006, p. 243) destaca que a reparação dos danos morais não pode mais operar no nível do senso comum e que a sua relevância atual impõe que se alcance um certo grau de tecnicidade para o conceito e que essa falta

\footnotetext{
${ }^{3}$ Segundo a Súmula 37 do Superior Tribunal de Justiça: "são cumuláveis as indenizações por dano material e dano moral oriundos do mesmo fato".
} 
de rigor científico na definição do dano moral termina por gerar "graves injustiças e incertezas ao jurisdicionados".

Partindo de uma revisão crítica do conceito, que questiona a possibilidade de toda dor, tristeza ou constrangimento configurar dano moral, verifica-se, então, a emergência de uma nova concepção, de natureza objetiva, que vincula o dano moral aos direitos da personalidade, considerando-o como uma lesão a esses direitos ou à própria dignidade da pessoa humana (MORAES, 2006, p. 246).

Neste contexto, o pressuposto do dano passa a se situar na própria atividade lesiva (dano normativo), não importando, para a sua configuração, as alteracões que eventualmente promova no estado anímico da vítima. Dor, sofrimento, humilhação e angústia tornam-se, assim, apenas consequências possíveis do dano moral, que devem ser consideradas no momento da sua quantificação, e não o dano moral em si.

Pode-se dizer, então, que o dano moral não está obrigatoriamente atrelado a alguma reação psíquica da vítima, de modo que, como bem percebe Sérgio Cavallieri Filho, “ pode haver ofensa à dignidade da pessoa humana sem dor, vexame, sofrimento, assim como pode haver dor, vexame e sofrimento sem violação da dignidade" (CAVALLIERI FILHO, 2012, p.89).

Como decorrência dessa progressiva objetivação do dano moral, a jurisprudência recente, sobretudo do Superior Tribunal de Justiça, vem dispensando a prova do dano moral quando este decorre da violação de direitos da personalidade. Compreede-se, aqui, que a gravidade do comportamento do agente aliada à constatação da ofensa ao bem juridico tutelado são suficientes para inferir a ocorrência de dano, cuidando-se, então, de hipótese de dano moral presumido ou in re ipsa.

A reparação do dano moral torna-se mais facilitada, pois passa a depender somente da prova do fato que lhe tenha dado causa. Assim, uma vez demonstrado o fato da violação ao direito da personalidade, o dano moral passa a ser encarado como fato notório (art. 374, I do CPC) ou como fato presumido pelo juiz por força da aplicação das regras de experiência (art. 375 do CPC) (AMARO, 2009, p. 167).

Compreendido o dano moral como ofensa à direito da personalidade ou como lesão à dignidade humana, chegou o momento de enfrentar a possibilidade de esta categoria de direitos também abarcar de direitos difusos e coletivos. É que será abordado no tópico a seguir. 


\section{DIREITOS DA PERSONALIDADE COMO CATEGORIA "ABERTA" , QUE TAMBÉM CONTEMPLA OS DIREITOS DIFUSOS E COLETIVOS.}

Os direitos da personalidade já foram definidos como "os direitos próprios do ser humano" (BORGES, 2009, p. 25) ou como "o conjunto de atributos inerentes à condição humana" CHAVES; ROSENVALD, 2016, p. 214).

Como bem observa Roxana Borges (2009, p. 25), eles não constituem, verdadeiramente, um direito à personalidade, uma vez que eles não têm a personalidade como objeto, cuidando-se, antes, de direitos decorrentes da personalidade, que derivam de algumas de suas qualidades, expressões ou projeções. Tratam-se, assim, de direitos vocacionados à concretização da cláusula geral de proteção da pessoa humana, contida no inciso III do art. $1^{\circ}$ da Constituição Federal.

Além de absolutos, imprescritíveis, vitalícios, de serem marcados por uma indisponibilidade relativa, os direitos da personalidade também apresentam um caráter necessariamente aberto, jamais podendo configurar numerus clausus, pois, à medida que as relações sociais se tornam mais complexas, emergem novas formas de violação à pessoa, que passam a demandar uma resposta jurídica.

Por isso, as listagens de direitos da personalidade constantes tanto na Constituição Federal quanto no Código Civil de 2002 têm um caráter meramente exemplificativo, não impedindo a identificação de direitos outros, que, embora não previstos de modo expresso, voltam-se à proteção da dignidade da pessoa humana.

Os direitos da personalidade, nesta linha, podem ser reputados como direitos em expansão, que sempre se ampliam com "a evolução legislativa e o desenvolvimento do conhecimento científico acerca do Direito” (BORGES, 2009, p. 25), impedindo, com isso, que novos e eventuais valores incorporados à personalidade fiquem sem a devida tutela jurídica. $^{4}$

\footnotetext{
${ }^{4}$ Essa compreensão aberta dos direitos da personalidade encontra-se, inclusive, firmada no Enunciado 274 da Jornada de Direito Civil que dispõe que: "Os direitos da personalidade, regulados de maneira não exautiva pelo Código Civil, são expressões da cláusula geral de tutela da pessoa humana, contida no art. $1^{\circ}$, III, da Constituição Federal”.
} 
Esse caráter expansivo dos direitos da personalidade fica muito evidenciado, hodiernamente, em relação às dimensões difusa e coletiva da personalidade, que tem ganhado destaque, sobretudo, com o sugimento e a consolidação da "sociedade de massa", que, colocando em marcha o progresso da técnica e a exarcebação da produção industrial, passa a expor a coletividade a uma série de novas ameaças, de difícil controle e gestão pelas instâncias administrativas. Tomem-se como exemplos as lesões ambientais, que terminam por privar a coletividade do acesso ao meio ambiente equilibrado ou as possíveis violações ocoasionadas por uma publicidade enganosa ou abusiva.

Nessa linha, repensar a categoria dos direitos da personalidade à luz das novas exigências sociais, de modo a englobar, ao lado dos direitos individuais, os direitos dos vulneráveis, como os consumidores, os idosos, as crianças e os adolescentes, os indígenas e os afetados pela danosidade ambiental é uma tarefa urgente para os operadores do Direito.

Essa função vem sendo assimilada aos poucos pelos Tribunais, como bem exemplifica o brilhante trecho do voto da Ministra Eliana Calmon, na apreciação do Resp. 1057274 / RS:

O dano moral extrapatrimonial atinge direitos de personalidade do grupo ou coletividade enquanto realidade massificada, que a cada dia mais reclama soluções jurídicas para sua proteção. É evidente que uma coletividade de índios pode sofrer ofensa à honra, à sua dignidade, à sua boa reputação, à sua história, costumes e tradições. Isso não importa exigir que a coletividade sinta a dor, a repulsa, a indignação tal qual fosse um indivíduo isolado. Estas decorrem do sentimento coletivo de participar de determinado grupo ou coletividade, relacionando a própria individualidade à ideia do coletivo. ${ }^{5}$

Neste julgado, o reconhecimento da existência do dano moral coletivo só foi possível a partir da compreensão dos direitos da personalidade como categoria aberta, que também abrange, dentre outros, o direito ao meio ambiente ecologicamente equilibrado e o direito dos povos indígenas, estes também indispensáveis para a concretização de uma vida sadia e com dignidade.

Trata-se também de reconhecer que o legislador brasileiro, ao lado dos direitos estritamente individuais, também conferiu à coletividade direitos informados por valores

\footnotetext{
${ }^{5}$ BRASIL. Superior Tribunal de Justiça. Acórdão em recurso especial n. 1057274 / RS. Relator: Ministra Eliana Calmon. Disponível em: <www.stj.jus.br>. Acesso em: 09 de setembro de 2016.
} 
extrapatrimoniais, de natureza transindividual, que deixam de ter o indivíduo, isoladamente considerado, como referência.

A partir dessas bases, observa-se uma consequente ampliação na própria compreensão do dano moral, que, como será aprofundado a seguir, deixa de se limitar à alteração de um estado anímico, inerente às pessoas naturais, para também alcançar o dever de reparar danos extrapatrimoniais de natureza difusa e coletiva (MELLO, 2014, p. $60)$.

\section{A CARACTERIZAÇÃO DO DANO MORAL COLETIVO NO DIREITO DO CONSUMIDOR.}

O Código Brasileiro de Defesa do Consumidor consagra, em seu art. $6^{\circ}$, VI, “a efetiva prevenção e reparação de danos patrimoniais e morais, individuais, coletivos ou difusos" como um direito básico do consumidor, acolhendo, assim, o princípio da reparação integral e deixando claro que, no âmbito das relações de consumo, a reparabilidade dos danos morais alcança tanto as lesões individuais quanto as de natureza coletiva.

Em sua dimensão individual, o dano moral consumeirista configura uma violação a direitos personalíssimos pertencentes ao consumidor e, em razão do seu caráter individual, a princípio, apenas o seu titular pode requerer a sua reparação, valendo-se, para tanto, das regras processuais tradicionais, devendo, os valores auferidos a título de indenização, ser a ele destinados, de forma direta. Excepcionalmente, estando caracterizada a presença de interesses individuais homogêneos, será possível o recurso à ação coletiva.

A apuração do dano moral individual segue a regra geral do Código de Defesa do Consumidor e, por isso, ressalvadas as hipóteses de prestação pessoal de serviço por profissional liberal (art. $14, \S 4^{\circ}$ do $\mathrm{CDC}$ ), basear-se-à na natureza objetiva da responsabilidade civil.

Quanto à fixação da indenização, inexistem atualmente parâmetros legais para a fixação do valor a ser pago à vítima, limitando-se o Código Civil a estabelecer, em seu art. 944, que a indenização deve medir-se pela extensão do dano. 
De acordo com Elisabete Amaro, a quantificação do dano moral individual deve levar em consideração a extensão do dano, confrontando-a com a capacidade econômica do lesante e observando, ainda, a repercussão do dano sob o prisma interno e externo (AMARO, 2009, p. 167). Deve a indenização, neste quadro, servir tanto como lenitivo, para eliminar ou diminuir a dor e o desconforto sofridos pela vítima, quanto como meio de inibir o ofensor, para que não volte a causar lesão extrapatrimonial.

Observe-se que admitir um efeito dissuasório para a indenização decorrente de dano moral não significa, necessariamente, defender a aplicação dos punitive damages neste campo. Apesar da sua crescente aceitação, a tese do dano moral punitivo encontra ainda fortes resistências doutrinárias, cuja discussão mais aprofundada não seria possível no curto espaço deste artigo. ${ }^{6}$

Já na sua acepção coletiva, o dano moral traduz-se numa lesão na esfera social de um grupo (determinável ou não) de sujeitos, que não se confunde com o patrimônio material ou moral dos indivíduos que o compõem. Trata-se da ofensa a interesses não patrimoniais coletivos, que apresentam uma base fática comum, ainda que não exista uma prévia relação jurídica entre os seus membros e acarreta um rebaixamento imediato da qualidade coletiva de vida.

Como observa observa Fernando Mello (2014, p.60), esse dano atinge o patrimônio moral transindividual, pertencente à coletividade, que, "embora considerada como ente despersonalizado, titulariza valores morais e apresenta um patrimônio ideal, que demanda proteção".

Nesta linha, o reconhecimento legal da coletividade como titular de bens imateriais juridicamente relevantes deve corresponder à existência de mecanismos adequados para a prevenção e a reparação das lesões que os afetem, justiticando, assim, a reparabilidade dos danos morais coletivos.

Segundo Steigleder (2004, p. 164), o fundamento para a sua admissibilidade é a existência de valores que norteiam a coletividade, concebida como um conglomerado de pessoas que vivem em determinado território e encontram-se unidas por fatores comuns.

\footnotetext{
${ }^{6}$ Para saber mais sobre a distinção entre o mero efeito dissuasório e a aplicação da teoria dos "punitive damages", vale a leitura do artigo: COSTA, Judith Martis; PARGENDLER, Maria Souza. Usos e abusos da função punitiva. Revista CEJ, Brasília, n. 28, p.15-32, jan./mar. 2005.
} 
Esses valores portam referência à comunidade, independentemente dos seus membros e, por isso, apresentam natureza autônoma e indivisível.

No entanto, o dano extrapatrimonial coletivo nem sempre foi interpretado dessa forma.

Numa primeira aproximação, este dano foi compreendido pela doutrina brasileira como uma lesão capaz de causar dor, sofrimento ou aflição a uma coletividade ou grupo de pessoas.

Nesse sentido, era a definição de Mirra (2010, p. 438), para quem o dano moral coletivo consistiria na dor ou no sentimento de frustração da sociedade. Para Paccagnella (2010, p. 594), o objetivo da responsabilização pelo dano moral coletivo era o mesmo do dano moral individual, ou seja, reparar o sofrimento, a dor, o desgosto do ser humano. A única diferença era que o dano extrapatrimonial coletivo referia-se ao sofrimento de diversas pessoas dispersas em certa coletividade ou grupo social (dor difusa ou coletiva).

Essa definição oferece problemas, pois, além da ofensa à integridade psicofísica da coletividade ser de questionável existência (BARBOSA; MULTEDO, 2014, p. 42), ela não se coaduna com a visão civil-constitucional em torno do tema.

Assim, apenas a partir de uma perspectiva objetiva de dano moral, que o compreende como lesão a determinada categoria de direitos e do acolhimento de uma concepção aberta de direitos da personalidade, que admite a sua extensão para alcançar os novos direitos, é possível avançar para a caracterização do dano moral coletivo nas relações de consumo.

Nesse sentido, os direitos dos consumidores devem ser compreendidos como direitos da personalidade, autônomos em relação aos direitos patrimoniais, pois a proteção desta categoria de sujeitos, vulneráveis no mercado de consumo, representa uma condição indispensável para o pleno desenvolvimento da personalidade humana.

Assim, através de uma visão renovada deste instituto, o dano extrapatrimonial consumeirista dispensa a existência de dor como elemento essencial, bastando, para a sua configuração, a ocorrência de ofensa a valores coletivos, compreendidos como o conjunto de crenças, costumes e significados, que compõem o patrimonio moral da coletividade.

Héctor Valverde Santana (2014, p. 148) destaca que o dano moral coletivo nas relações de consumo pode se configurar em frequentes situações como na publicidade 
discriminatória de parcela de consumidores, na venda ou exposição de produtos inseguros, na privação de serviço público essencial, ou no descumprimento generalizado de contrato de consumo.

Embora a sua aceitabilidade seja crescente, ainda existem, na doutrina, autores contrários à reparabilidade do dano moral coletivo. As principais objeções ao seu reconhecimento fundam-se no requisito da pessoalidade do dano, na ausência de sujeito individual lesado, na dificuldade de se identificar os lesados e para provar, quantificar e reclamar judicialmente a reparação (GALDÓS, 2009, p. 289).

É certo, porém, que, se problemas existem em torno do tema, a sua solução não passa pela mera negação da sua existência, cabendo, assim, aos juristas a tarefa de adaptar os mecanismos da responsabilidade civil às peculiaridades do dano moral coletivo, como forma de garantir o atendimento aos ditames do princípio da reparação integral.

Ademais, neste cenário, parece, no mínimo, contraditório admitir-se a reparação do dano moral que afeta as pessoas jurídicas e negar a reparabilidade do dano que atinge os valores imateriais que regem a coletividade.

Deve-se, então, avançar e admitir, por exemplo, que o requisito da pessoalidade não tem aplicabilidade no âmbito do dano moral coletivo, diante da frequente impossibilidade de se identificar, com precisão, as vítimas do evento e de se aferir individualmente a lesão.

Contudo, tal como ocorre com os danos em geral, não é qualquer perturbação que pode configurar dano extrapatrimonial coletivo. Neste sentido, a jurisprudência do STJ tem se firmado no sentido de que apenas quando o fato transgressor for relevante, ultrapassando os limites de tolerabilidade, haverá dano moral coletivo reparável.

Diversamente do dano moral individual, aqui o agravo é coletivo e não se traduz pessoalmente a seus membros, por conta disso, a sua tutela processual deve ser feita por meio de instrumentos processuais adequados, de índole coletiva, e eventual indenização deve ser destinada ao Fundo de Reparação dos Bens Lesados, previsto no art. 13 da Lei da Ação Civil Pública, voltando-se para a própria coletividade.

Do ponto de vista probatório, por ser menos evidente, o dano moral coletivo tem uma prova ainda mais difícil, devendo, por isso, na mesma linha do dano moral individual, ser presumido em virtude da gravidade da lesão. 


\section{O DANO MORAL COLETIVO NAS RELAÇÕES DE CONSUMO SEGUNDO A JURISPRUDÊNCIA DO SUPERIOR TRIBUNAL DE JUSTIÇA.}

O dano moral coletivo percorreu um longo caminho até ter a sua reparabilidade reconhecida pelos tribunais.

O Superior Tribunal de Justiça analisou a juridicidade do dano moral coletivo pela primeira vez apenas em 2006, por meio do Recurso Especial 598281 / MG, relatado pelo Min. Luiz Fux.

Tratava-se de recurso extraordinário contra acórdão do Tribunal de Justiça de Minas Gerais, que entendeu pela impossibilidade de condenação de dano moral coletivo em sede de ação civil pública na qual se discute a reparação de danos ao meio ambiente.

Embora o voto do relator tenha sido favorável ao reconhecimento do dano ambiental moral coletivo, a primeira turma terminou perfilhando o entendimento do Min. Teori Zavascki.

Para este ministro, apesar de o dano ambiental ou ecológico poder, em tese, acarretar também o dano moral, a vítima do dano moral deve ser, necessariamente, uma pessoa, pois este dano não seria compatível com a transindividualidade da lesão. A ementa foi elaborada da seguinte forma:

PROCESSUAL CIVIL. AÇÃO CIVIL PÚBLICA. DANO AMBIENTAL. DANO MORAL COLETIVO. NECESSÁRIA VINCULAÇÃO DO DANO MORAL À NOÇÃO DE DOR, DE SOFRIMENTO PSÍQUICO, DE CARÁTER INDIVIDUAL. INCOMPATIBILIDADE COM A NOÇÃO DE TRANSINDIVIDUALIDADE (INDETERMINABILIDADE DO SUJEITO PASSIVO E INDIVISIBILIDADE DA OFENSA E DA REPARAÇÃO). RECURSO ESPECIAL IMPROVIDO .

O equívoco desta decisão está no não reconhecimento de que, ao lado das lesões individuais, no dano moral coletivo, existe a ofensa a valores relevantes para a sociedade que, em razão do seu caráter comum, não são usufruídos de maneira individual ou exclusiva. Nessas lesões, a vítima direta é a coletividade e não os indivíduos isoladamente considerados, ainda quando as consequências destes danos repercutam sobre eles (GALDÓN, 2009, p. 289). 
Três anos mais tarde, a segunda turma teve oportunidade de apreciar a questão, por meio do Recurso Especial 1057274 / RS, de relatoria da Min. Eliana Calmon.

O acórdão debateu a possibilidade de configuração de dano moral coletivo perpetrado por empresa de transporte que exigia procedimento de cadastramento de idosos para que estes pudessem dispor do benefício do passe livre. Eis a ementa do acórdão:

ADMINISTRATIVO - TRANSPORTE - PASSE LIVRE - IDOSOS -
DANO MORAL COLETIVO - DESNECESSIDADE DE
COMPROVAÇÃO DA DOR E DE SOFRIMENTO - APLICAÇÃO
EXCLUSIVA AO DANO MORAL INDIVIDUAL -
CADASTRAMENTO DE IDOSOS PARA USUFRUTO DE DIREITO
- ILEGALIDADE DA EXIGENCIA PELA EMPRESA DE
TRANSPORTE - ART. 39, § $1^{\circ}$ DO ESTATUTO DO IDOSO - LEI
10741/2003 VIAÇÃO NÂO PREQUESTIONADO. ${ }^{7}$

Este julgado, de maneira mais avançada, afirmou o caráter transindividual do dano moral coletivo e sua aptidão para atingir uma classe específica ou não de pessoas, compreendendo que a sua comprovação se dá pela "presença de prejuízo à imagem e à moral coletiva dos indivíduos enquanto síntese das individualidades percebidas como segmento, derivado de uma mesma relação jurídica-base". Reconheceu que, em sua dimensão coletiva, o dano moral dispensa a comprovação de dor, de sofrimento e de abalo psicológico, inaplicável aos interesses difusos e coletivos.

A partir destes pressupostos, entendeu que a submissão dos idosos a procedimento de cadastramento para o gozo do benefício do passe livre, com o deslocamento custeado pelos interessados, feria o art. $39, \S 1^{\circ}$ do Estatuto do Idoso, configurando dano moral coletivo ressarcível.

Ao apreciar o Resp. 1.221.756 - RJ, em fevereiro de 2012, a terceira turma condenou uma instituição bancária ao pagamento de $\mathrm{R} \$ 50.000,00$ (cinquenta mil reais), a título de danos morais coletivos, em razão de impor aos consumidores com dificuldades de locomoção a exigência de subir lances de escada para obter atendimento, compreendendo que:

Não é razoável submeter aqueles que já possuem dificuldades de locomoção, seja pela idade, seja por deficiência física, ou por causa transitória, à situação desgastante de subir lances de escadas, exatos 23

\footnotetext{
${ }^{7}$ BRASIL. Superior Tribunal de Justiça. Acórdão em recurso especial n. 1057274 / RS. Relator: Ministra Eliana Calmon. Disponível em: <www.stj.jus.br>. Acesso em: 09 de setembro de 2016.
} 
degraus, em agência bancária que possui plena capacidade e condições de propiciar melhor forma de atendimento a tais consumidores. ${ }^{8}$

Mais recentemente, o STJ reconheceu, no Resp. 1.397.870 - MG, julgado em dezembro de 2014, a presença de dano moral coletivo decorrente da prática de venda casada por operadora de telefonia, que oferecia aos consumidores linhas telefônicas com valores mais atrativos do que os da concorrência, condicionando, no entanto, o benéficio à aquisição de um aparelho telefônico por ela comercializado. Na linha do julgado:

\begin{abstract}
A prática de venda casada por parte de operadora de telefonia é capaz deromper com os limites da tolerância. No momento em que oferece aoconsumidor produto com significativas vantagens - no caso, o comércio de linha telefônica com valores mais interessantes do que a de seus concorrentes - e de outro, impõe-lhe a obrigação de aquisição de um aparelho telefônico por ela comercializado, realiza prática comercial apta a causar sensação de repulsa coletiva a ato intolerável, tanto intolerável que encontra proibição expressa em lei.
\end{abstract}

O acórdão considerou que afastar a incidência de dano moral difuso, na hipótese, seria o mesmo que fazer tabula rasa da proibição elencada no art. 39, I, do CDC legitimando práticas comerciais que afrontem os mais basilares direitos do consumidor.

Verifica-se, a partir da análise destes acórdãos, que os tribunais nacionais têm amadurecido a ideia de dano moral coletivo nas relações de consumo, apontando para a tendência doutrinária que admite a sua reparabilidade integral, independentemente da possibilidade de mensuração individual da ofensa a interesses difusos ou coletivos da comunidade ou da existência de prova de que houve dor, sofrimento ou lesão psíquica aos indivíduos.

\title{
6 CONCLUSÕES.
}

De tudo que foi abordado no presente artigo, restam como conclusões que:

1. Código Brasileiro de Defesa do Consumidor estruturou um sistema avançado de responsabilidade civil, assegurando a reparabilidade tanto dos danos materiais quanto morais, seja na sua dimensão individual ou coletiva;

\footnotetext{
${ }^{8}$ BRASIL. Superior Tribunal de Justiça. Acórdão em recurso especial n. 1.221.756 - RJ. Relator: Ministro Massami Uyeda. Disponível em: <www.stj.jus.br>. Acesso em: 09 de setembro de 2016.
} 
2. A despeito dos significativos avanços doutrinários e jurisprudenciais, persistem dificuldades na caracterização do dano moral coletivo incidente nas relações de consumo, sobretudo por conta da falta de consenso em torno do conceito dano moral e em razão da tentativa de se realizar, nesta esfera, uma mera transposição da doutrina tradicional do dano moral, sem as necessárias adaptações;

3. Sobre o conceito de dano moral, constatou-se a tendência atual de defini-lo de uma maneira mais objetiva, como ofensa a direito da personalidade ou como lesão à dignidade humana;

4. A respeito dos direitos do personalidade, verificou-se que eles constituem uma categoria aberta, submetida a constantes adaptações por força das mudanças sociais, englobando, hoje, ao lado dos direitos individuais, também os direitos difusos e coletivos;

5. Como consequência destes fatores, verifica-se uma ampliação na própria compreensão do dano moral, que deixa de se limitar à alteração de um estado anímico, inerente às pessoas naturais, para também alcançar o dever de reparar danos extrapatrimoniais de natureza difusa e coletiva;

6. Assim, o dano moral coletivo nas relações de consumo foi caracterizado como a lesão que afeta o patrimonio moral da coletividade, acarretando um rebaixamento imediato da qualidade coletiva de vida, independentemente da existência de dor como elemento essencial;

7. O caráter coletivo desse dano passa a exigir, contudo, uma revisão dos dogmas clássicos da responsabilidade civil, que deve se adaptar às suas peculiaridades.

8. Por fim, realizou-se um estudo das recentes decisões do Superior Tribunal de Justiça, constatando-se a progressiva recepção a essas idéias, apontando para um panorama que admite a sua reparabilidade integral do dano moral coletivo, independentemente da possibilidade de mensuração individual da ofensa ou da existência de prova de que houve dor, sentimento ou lesão psíquica aos indivíduos.

\section{REFERÊNCIAS BIBLIOGRÁFICAS}

AMARO, Elisabete Aloia. Responsabilidade civil por ofensa aos direitos da personalidade. In: NERY, Rosa Maria de Andrade; DONNINI. Responsabilidade civil: estudos em homenagem ao professor Rui Geral do Camargo Viana. São Paulo: RT, 2009. 
BARBOSA, Fernanda Nunes; MULTEDO, Renata Vilela. Danos extrapatrimoniais coletivos. Revista de Direito do Consumidor, ano 23, vol.93, mai-jun/2014.

BORGES, Roxana Brasileiro. Direitos de personalidade e autonomia privada. 2 ed. São Paulo: Saraiva, 2009.

BRASIL. Superior Tribunal de Justiça. REsp 26975 / RS, Rel. Ministro Aldir Passarinho Junior, julgamento em 18/12/2001.

CARPENA, Heloísa. Dano moral coletivo nas relações de consumo. In:TEPEDINO, Gustavo; FACHIN, Luiz Edson (coord.) O direito e o tempo: embates jurídicos e utopias contemporâneas. Estudos em homenagem ao Professor Ricardo Pereira Lira. Rio de Janeiro: Renovar, 2008.

CAVALliERI FILHO, Sérgio. Programa de Responsabilidade Civil. 10 ed. rev. e atual. São Paulo: Atlas, 2012.

COSTA, Judith Martis; PARGENDLER, Maria Souza. Usos e abusos da função punitiva. Revista CEJ, Brasília, n. 28, p.15-32 , jan./mar. 205

FARIAS, Cristiano Chaves de; ROSENVALD, Nelson. Curso de Direito Civil: parte geral e LINDB. 14 ed. rev., ampl. e atual. Salvador: Juspodium, 2016.

FLUMIGNAN, Silvano José Gomes. Uma nova proposta para a diferenciação entre o dano moral, o dano social e os punitive damages. Revista dos Tribunais, São Paulo , v.104, n.958, p. 119-147, ago./2015.

GALDÓS, Jorge Mario. El daño moral colectivo: su problemática actual. In: LORENZETTI, Ricardo Luis (dir). Derecho ambiental y daño. Buenos Aires: La Ley, 2009.

MARTINS, Guilherme Magalhães. Dano moral coletivo nas relações de consumo. Revista de Direito do Consumidor, São Paulo, v.21, n.82, p. 87-109, abr./jun. 2012.

MELLO, Fernando de Paula Batista. O dano não patrimonial transindividual. Revista de Direito do Consumidor, São Paulo , v.23, n.96, p. 41-74, nov./dez. 2014.

PACCAGNELLA, Luis Henrique. Dano moral ambiental. In: Nery Júnior, Nelson; NERY, Rosa Maria de Andrade. Responsabilidade Civil: doutrinas essenciais. v. 7. São Paulo: Editora Revista dos Tribunais, 2010.

SANTANA, Hector Valverde. Dano moral no direito do consumidor. 2 ed. rev. atual e ampl. São Paulo: RT, 2014.

SCHEREIBER, Anderson. Novos paradigmas da responsabilidade civil: da erosão dos filtros da reparação à diluição dos danos. 2. ed. São Paulo: Atlas, 2009. 